\title{
Analysis of subjective experiences of breast cancer patients receiving hypnosis, music, or special attention, during chemotherapy treatment: A content analysis
}

\author{
A VARGAY ${ }^{1,2 *}$, ZS KALÓ ${ }^{2}$, O ZSIGMOND $^{1,2}$, E JÓZSA $^{2}$, T THURZÓ $^{2}$, G KÓBER $^{2}$ and É BÁNYAI ${ }^{2}$ \\ ${ }^{1}$ Doctoral School of Psychology, Eötvös Loránd University, Budapest, Hungary \\ ${ }^{2}$ Institute of Psychology, Eötvös Loránd University, Budapest, Hungary
}

(Received: August 31, 2018; revised manuscript received: November 20, 2018; accepted: November 30, 2018)

\begin{abstract}
Purpose: The effectiveness of psychotherapeutic techniques with breast cancer patients has been extensively studied; however, there is limited information available on subjective experiences of patients. The aim of this study was to establish a category system and describe the characteristics of patients' subjective experiences in three different intervention groups: hypnosis, music, and special attention. Materials and methods: Content analysis of short interviews after 21 sessions of intervention was conducted to examine and compare subjective experiences in hypnosis, music, and special attention. Two types of coding system were developed: Characteristics of Involvement (CI) and Intensity of Involvement (II). Results: Based on CI, the most dominant subjective experience of breast cancer patients was the "Pleasant Somatic Experience." Furthermore, "Visualisation of Symbols" was the most frequent in the hypnosis intervention. Based on II, most common experience of the special attention group was coded as "low intensity." The frequencies of "low/high intensity" experiences were different between hypnosis and music interventions. "High intensity" was more dominant in hypnosis than music intervention. Conclusions: Both category systems may be reliable tools to examine patients' subjective experience. Hypnosis as intervention can result in more extended subjective experiences in CI and II.
\end{abstract}

Keywords: breast cancer, hypnosis, subjective experience, content analysis

\section{INTRODUCTION}

Although the majority of cancer patients can successfully cope with and be able to face all the negative emotional stress accompanying the examinations and treatments of their disease, it appears that at least $30 \%$ - according to some studies, up to $60 \%$ - of cancer patients experience a level of distress that would require professional psychological or psychiatric help. The most common problems are depression, anxiety disorders, and adjustment disorders [1-3]. Nowadays, it became evident that holistic oncological service cannot lack available psychosocial help from professionals. Numerous psychotherapeutic techniques have become available to improve the psychological aspects of the treatment, quality of life, and coping mechanisms of cancer patients. The effectiveness of these techniques has been extensively studied $[4,5]$; however, there is limited information available on the types of subjective experiences for patients undergoing these interventions.

Patients' attentional focus spontaneously narrows due to the emotional strain and psychological distress caused by the diagnosis and the difficulties of the treatment, with information processing becoming dominated by emotional impacts. This spontaneously developed altered state of consciousness is an uncontrolled negative trance, which theoretically can be transferred to a positive one, using techniques involving controlled altered states of consciousness such as music or hypnosis [6-8]. Both hypnosis and music are frequently used with oncology patients and have a long a history in helping in the same areas of the cancer continuum, i.e., symptom management, procedural pain, controlling side effects, as well as improving psychological well-being and quality of life [6,9-18].

The process of analysing the subjective experience of controlled altered states of consciousness has mainly been established and represented in the literature of hypnosis. The attempt to understand the private experience of a hypnotised person in experimental circumstances resulted in the development of several distinctive methods and instruments for measuring the so-called subjective depth of hypnosis. Most of these involve paper-and-pencil questionnaires, which are to be filled in by the subject retrospectively and were standardised and used in healthy population [19-22].

Relatively few studies explore the nature of experiences of cancer patients undergoing adjunctive therapies involving altered states of consciousness. In these studies, it became clear that the quality of patients' experience affects the perceived or measured benefits of the interventions. Walker et al. [23] asked cancer patients in a relaxation combined

* Corresponding author: Adrienn Vargay; Institute of Psychology, Doctoral School of Psychology, Eötvös Loránd University, Izabella u. 46, H-1064 Budapest, Hungary; E-mail: vargay. adrienn@gmail.com

This is an open-access article distributed under the terms of the Creative Commons Attribution-NonCommercial 4.0 International License, which permits unrestricted use, distribution, and reproduction in any medium for non-commercial purposes, provided the original author and source are credited, a link to the CC License is provided, and changes - if any - are indicated. 
with guided imagery study to keep a journal of their experiences, keeping track of their exercises, any difficulties experienced in the performance, as well as rating how vivid the imagery was (with ratings of $0-10$ on a Likert scale). In line with their findings, while the control and treatment groups showed no difference in primary response to the chemotherapy, there proved to be a marked difference in clinical response, showing correlation with the vividness ratings for the visualisation exercises. Eremin et al. [24] used a similar methodology to investigate the immunomodulatory effects of relaxation training and guided visualisation exercises for patients suffering from breast cancer. Their results showed significant correlation between the vividness of imagery, as rated by the patient, and the baseline-corrected values for natural killer and lymphokine-activated killer cell activity, as well as interleukin 1 beta levels. In a study by Kwekkeboom and Wanta [25], the reduction in pain level of cancer patients with guided imaginary showed positive correlation with better expected disease outcomes and with more vivid imagery. Kwekkeboom, Hau, Wanta, and Bumpus [26] performed a retrospective study on how the efficacy of relaxation and visualisation treatment techniques could be affected by the perceptions and expectations of patients. Their conclusion was that the patients' active, motivated involvement in the treatment showed correlation with its ultimate effectiveness.

Regarding music interventions with oncology patients, in line with the findings of Potvin, Bradt, and Kesslick [27], symptom management is not a linear process (i.e., receiving an intervention that helps to relieve symptoms), rather it requires intrapsychic involvement on the side of the patients to achieve a more holistic well-being. The authors also recommend for future research to incorporate intrapsychic content when examining interventions for symptom management.

These findings demonstrate that there is an important relationship between the subjective experience of patients, their active involvement, the vividness of imagery, and the efficiency of the method used; therefore, patients' subjective experience should be better understood and analysed.

The aim of this study is to introduce an encoding system, which helps to describe the personal experiences and subjective involvement of breast cancer patients in hypnosis and in music or special attention as control condition. The analysis of subjective experiences is based on spontaneous reports, and is registered in vivo, immediately following the interventions. This allows for a complex and multidimensional assessment. To our knowledge, personal experience of breast cancer patients undergoing hypnosis/music/special attention has not been examined in such detail yet. Furthermore, the aim was to test the hypothesis that hypnosis as an adjunctive treatment evokes more vivid and intense images as subjective experience than music or special attention. More extended subjective experience can be behind in a more intense intrapsychic involvement.

\section{MATERIALS AND METHODS}

\section{Description of the study framework}

The data presented in this paper are a part of a prospective, randomised, single-blind, controlled study entitled
"Psychological Resources and Healing" [Research ethical approval: 15530-0/2010-1018EKU (670/PI/10) and 39447-/ 2013/EKU (465/2013), supported by the Hungarian Scientific Research Fund - OTKA K109187, Principal investigator Prof. Éva Bányai], which aims to prove that hypnosis as an adjunctive treatment for breast cancer patients has a beneficial effect on quality of life, coping capacity, and immune activity. The effectiveness of hypnosis is compared with music sessions and special attention, which are provided throughout the course of chemotherapy. Patients are following a standardised taxane-antacycline chemotherapy protocol for 24 weeks [28, 29].

\section{Participants}

The study involves histologically confirmed, HER2negative, axillary lymph node-positive or high-risk, lymph node-negative breast cancer patients without distant metastases, who are candidates for adjuvant chemotherapy based on St. Gallen's Consensus Guideline in 2011 [30]. All patients undergo complete surgical resection. The subjects $(n=103)$ were randomised to receive hypnosis $(n=38)$ or music $(n=42)$ or recruited for special attention $(n=23)$ as a control condition. Participation was voluntary with a signed informed consent.

\section{Description of interventions}

Prerecorded hypnosis or music was administered for 24 weeks on 21 occasions, while patients were receiving chemotherapy or waiting for blood test results in the presence of a hypnotherapist. Hypnosis began with standardised hypnotic induction and was followed by various therapeutic and post-hypnotic suggestions. It contained images to help relieve stress-induced anxiety, as well as metaphors for egostrengthening, helping to increase motivation for recovery, dealing with the side effects of chemotherapy (nausea and hair loss), activating the inner healing resources, and facilitating immune functions. The music group listened to a selection of classical music. It was designed to match the themes, moods, and dynamics of hypnosis, lasting as long as the hypnosis sessions. Special attention was provided for all patients above standard medical care. The same amount of attention was provided for those patients by the members of the research team who did not receive extra intervention (hypnosis/music). Special attention consisted of extra social support, supportive care, as well as inquiries about emotional and physical well-being.

\section{Data collection}

Patients' subjective experience of altered state of consciousness was registered through face-to-face interviews following each therapeutic session by research assistants. Patients were asked to report on their thoughts and feelings after each hypnosis or music session, or in the case of the special attention group, after receiving chemotherapy, or while waiting for their blood test results. The first questions asked of the patients were standardised as "Please tell us, in your own words, everything you have felt and experienced since listening to the hypnosis/music" and for the group with special attention as "Please tell us, in your own words, 
everything you have felt and experienced since receiving the chemotherapy." However, assistants were allowed to raise further questions to clarify patients' statements, to facilitate more detailed explanations, or to reflect on their emotions in a non-directive way. All assistants were trained in the above-described process. The patients' answers were recorded on an MP3 player and later transcribed verbatim for further analysis. The verbatim texts serve as the basis for content analysis. The lengths of the answers given varied from 5 to 2,279 words, with the mean 203 .

\section{Data analysis}

Data analysis was performed on the experience of hypnosis, music, and special attention treatment received during chemotherapy. Our methodology was a combination of a phenomenological approach (similar to Smith, Jarman, and Osborn's [31] interpretative phenomenological analysis method) and content analysis methods [32]. Our goal was to explore the individual's personal perception and to create a system of categories about the experience itself.

The data analysis procedure consisted of two phases. In the first phase, the method used was phenomenologyoriented and inductive, whereas the second phase was a systematic content analysis for codifying the system.

A total of 351 sessions were analysed. Two independent researchers [33] read the reports of hypnosis experiences, as well as the session narratives for the music and special attention sessions. Each transcript was read several times to ensure familiarity with the written content. The researchers searched for emerging themes in the patients' self-disclosure similar to the study of Downe-Wamboldt [32], and then defined categories that could describe the involvement in the altered states of consciousness. One of the researchers collected a list of basic themes and subcategories. The list of basic themes was then given to the other researcher, who was instructed to produce subcategories for them. These categories were then compared with the original list once more. These lists were repeatedly compared with the interview data, until the two researchers were in agreement regarding the basic themes and subcategories. Two other independent raters were tasked with measuring the reliability of the coding system, through encoding a total of 1,568 hypnosis/music/special attention sessions. The analysed text comprises a total of 318,786 words.

\section{RESULTS}

\section{Description of the encoding system}

Codes for the Characteristics of Involvement (CI). The grouping of the emerging categories reflects a certain measure of Intensity of Involvement (II) in the available support reported by the patients, as well as the patients' intrapsychic work. The CI consists of the following codes: (a) somatic complaints, (b) internal or external disturbances, (c) pleasant somatic experiences, (d) non-verbal sensory experiences, (e) positive or negative personal memories, (f) visualisation of symbols, and (g) elaboration of symbols. The codes of CI are described in more details in Table 1.

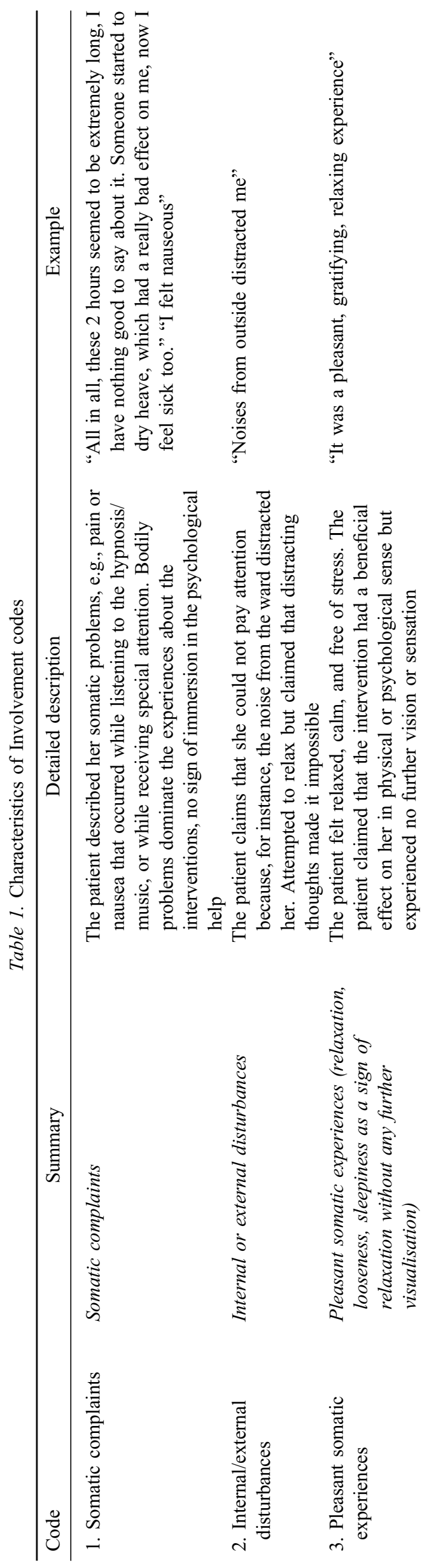

72 | Developments in Health Sciences 1(3), pp. 70-77 (2018) 


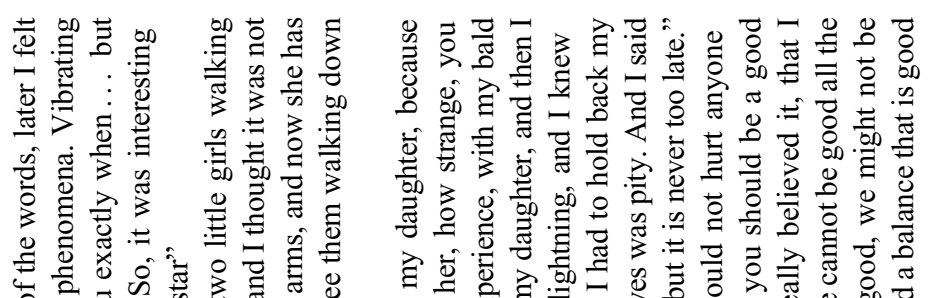

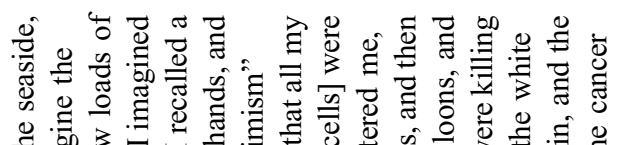

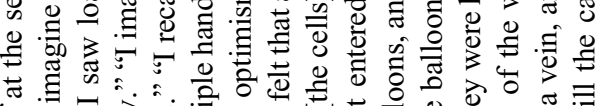

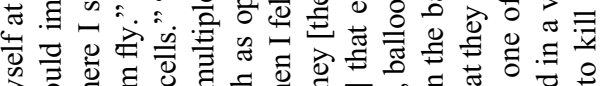

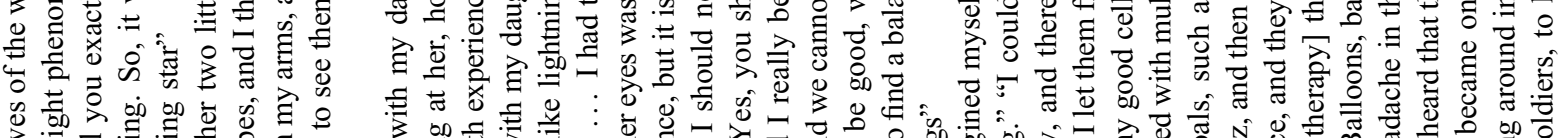

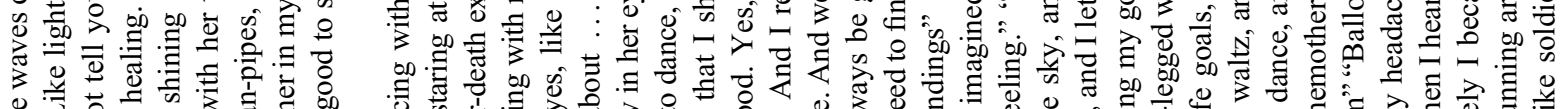

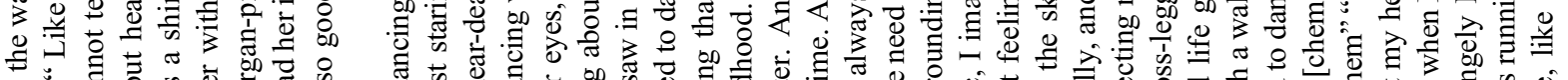

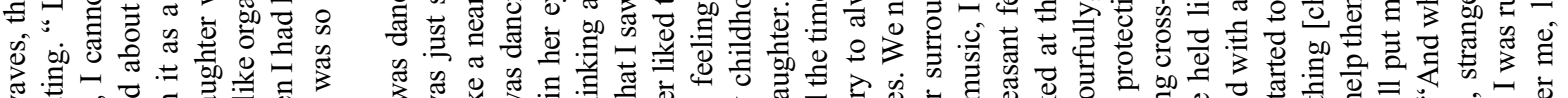

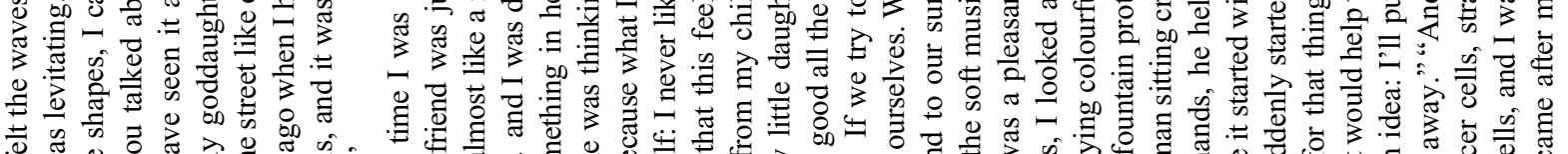

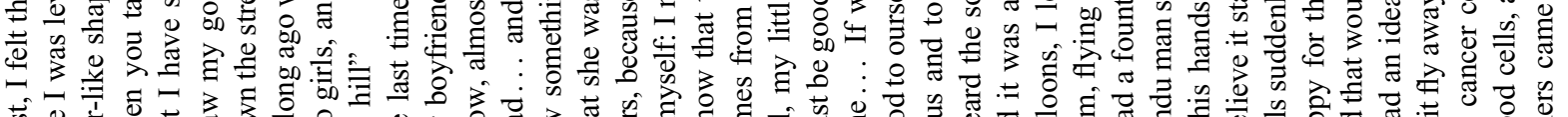

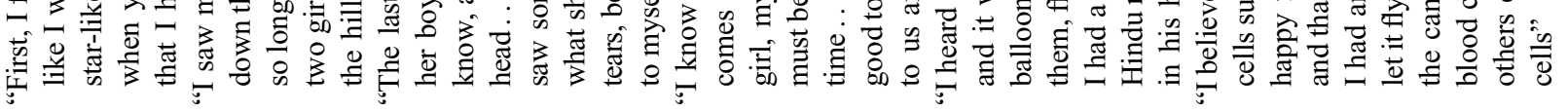
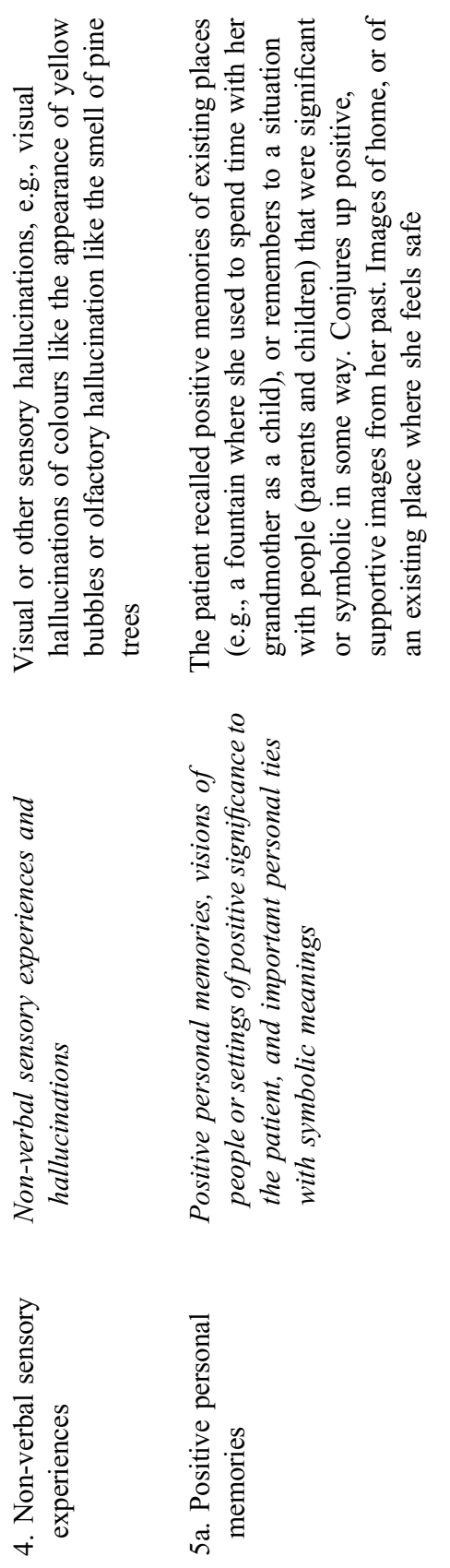
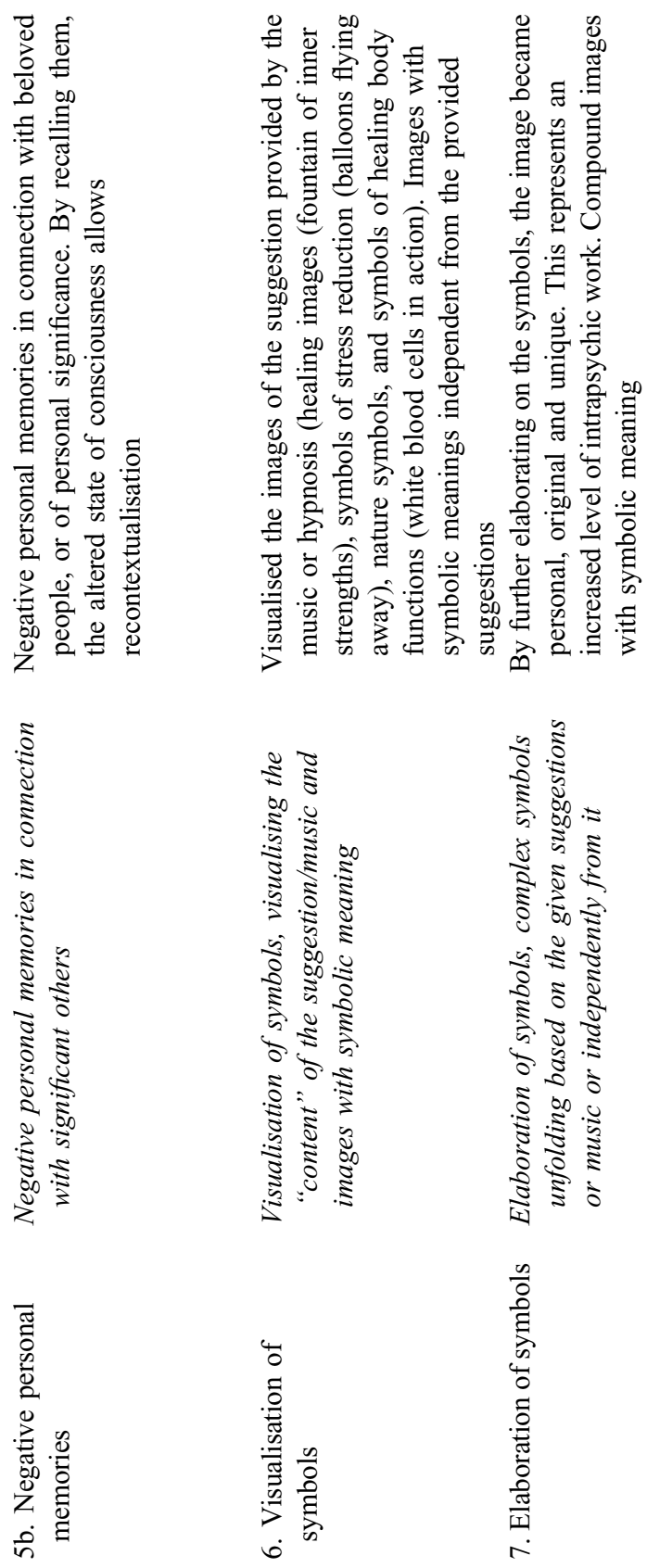
The first four categories can be interpreted to represent an increasing involvement in the therapeutic interventions. Those who reported somatic complaints or internal/external disturbances were less likely to become involved in intrapsychic work than those who reported having had a pleasant somatic experience or a non-verbal sensory experience. The further three categories (personal memories, visualisation, and elaboration) do not represent an increasing involvement, rather a separable characteristic of involvement.

Codes for II. Once the first set of ratings was completed, the need for a more general category system became apparent. The reason was that even though the categories represented a certain, distinct type of intensity, the researchers found that at times, behind more intense categories there was a less intense involvement or vice versa. Therefore, two subcategories were created. Based on evaluating an experience, codes were assigned high or low levels of intensity.

Low-intensity involvement: The patient appears not to be involved in the process or shows signs of resistance. In addition, the patient does not report subjective experiences and demonstrates no sign of intrapsychic work.

High-intensity involvement: The patient achieves a relaxed state, with optimal signs of an altered state of consciousness (e.g., sensory hallucinations) or the patient is involved in the process, discovering content with personal significance or symbolic meaning. There is clear sign of intrapsychic work.

\section{Raters' agreement}

Raters' agreement across CI. The two independent raters involved for measuring the reliability of the coding system discovered a total of 3,408 codes. There were 186 codes that were only discovered by Coder 1 , and 172 that were only discovered by Coder 2 . The number of matching codes was high: 2,930 , resulting in $96.2 \%$ of agreement between the coders. For the further analyses, the codes discovered by both raters were taken into account.

Interrater reliability of the two subcategories: II. The measure of agreement between the two independent raters was calculated by Cohen's $\kappa$. The value of kappa is 0.951 $(p<.001)$, which corresponds to a strong, almost perfect agreement between the two raters. As shown in Table 2, the two raters had a total of 1,532 matched cases (out of 1,568 hypnosis/music/special attention experiences). Most of the experiences fall into the category of low intensity (965), with the coders agreeing in 959 cases. The remaining experiences fall into the high-intensity category (603), with the coders agreeing in 573 cases. Raters had $99.0 \%$ agreement for high and $97.0 \%$ for low-intensity experiences. Overall, our results show that trained raters can reliably judge the intensity of experience using the subcategory system and can accurately determine whether a given experience is of low or high intensity.

\section{Distribution of codes}

Distribution of codes: $C I$. The most common code was pleasant somatic experience in all three intervention groups: raters found the category applicable 1,014 times. Somatic complaints (695), internal/external disturbances (409), visualisation of symbols (469) all had a high rate of occurrence as well. Non-verbal sensory experiences (88), positive personal memories (148), and elaboration of symbols (98) occurred in the reports of a relatively small number of patients. Negative personal memories were discovered only 10 times, which may argue for merging or eliminating this category altogether.

In the hypnosis group, the most dominant category was pleasant somatic experience $(27.4 \%)$, which is immediately followed by visualisation of symbols $(24.6 \%)$. In the music group, pleasant somatic experience was the most dominant (38.6\%), followed by somatic complaints $(25.1 \%)$. Categories representing more involvement, such as visualisation of symbols $(10.2 \%)$ and elaboration of symbols $(2 \%)$, were less likely to appear in the hypnosis group. In the special attention group, pleasant somatic experiences was the most dominant as well $(46.6 \%)$, followed by somatic complaints (38.5\%). Table 3 shows the distribution of codes between the three intervention groups according to their intensity of CI.

Distribution of codes in groups: II. To calculate the distribution of codes in groups, only the matching codes were used. Based on the results, almost all the experience of the special attention group fell into the low-intensity category $(93.2 \%)$. In the hypnosis group, the majority of patients reported high-intensity involvement $(61.9 \%)$, whereas in the music group, low-intensity involvement was the most dominant $(69.3 \%)$. The association between the groups (hypnosis vs. music) and the involvement (low vs. high) was statistically significant $\left[\chi^{2}(2)=299.763, p<.001\right.$, Cramer's $V=0.44]$. Table 4 shows the frequency and percentage of II codes.

Table 2. Agreement between coders in the subcategory system

\begin{tabular}{|c|c|c|c|c|c|}
\hline & & & \multicolumn{2}{|c|}{ Coder 2} & \multirow[b]{2}{*}{ Total } \\
\hline & & & Low intensity & High intensity & \\
\hline \multirow[t]{4}{*}{ Coder 1} & Low intensity & Case & 959 & 30 & 989 \\
\hline & & $\%$ within Coder 1 & 97.0 & 3.0 & 100.0 \\
\hline & High intensity & Case & 6 & 573 & 579 \\
\hline & & $\%$ within Coder 1 & 1.0 & 99.0 & 100.0 \\
\hline \multirow[t]{2}{*}{ Total } & & Case & 965 & 603 & 1,568 \\
\hline & & $\%$ within Coder 1 & 61.1 & 38.5 & 100.0 \\
\hline
\end{tabular}


Table 3. The distribution of CI codes

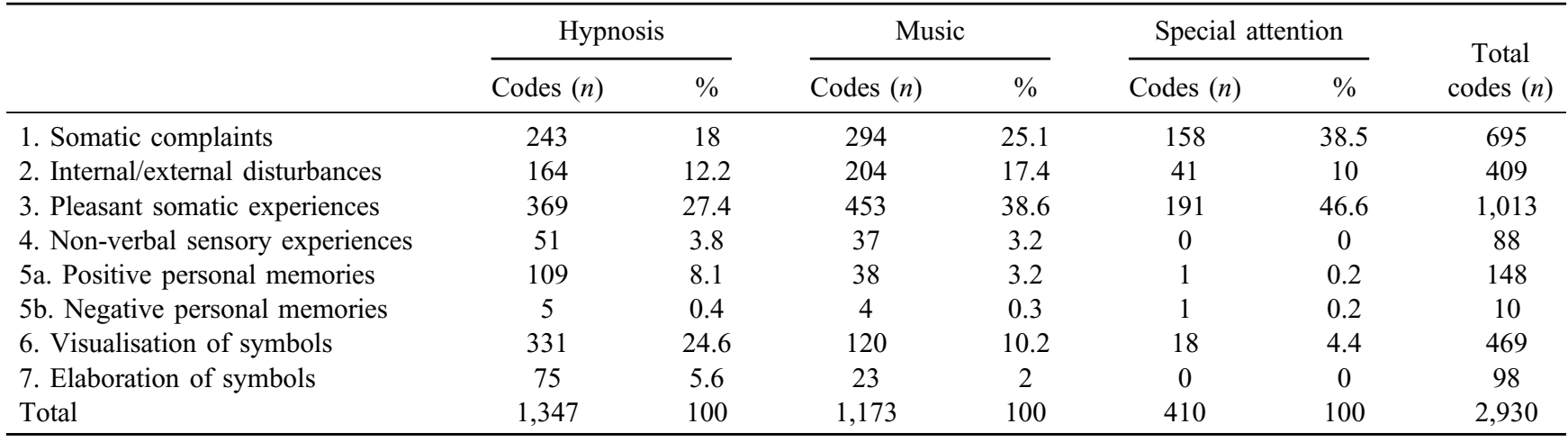

Table 4. The frequency and percentage of II codes

\begin{tabular}{lccccc}
\hline & \multicolumn{2}{c}{ Low } & & \multicolumn{2}{c}{ High } \\
\cline { 2 - 3 } \cline { 6 - 6 } & Frequency & $\%$ & & Frequency & $\%$ \\
\hline Hypnosis & 221 & 38.1 & & 363 & 61.9 \\
Music & 441 & 69.3 & & 191 & 38.7 \\
Special attention & 297 & 93.2 & & 19 & 6.8 \\
\hline
\end{tabular}

\section{DISCUSSION AND CONCLUSIONS}

In this study, the subjective level of involvement in hypnosis, music, or special attention treatment was examined in a homogeneous group of breast cancer patients. To our knowledge, this is the first study analysing spontaneous reports in such detail, which are registered in vivo, immediately following these types of interventions. Two types of encoding systems were developed, $C I$ measuring personal involvement based on analysing the appearance of certain themes of different categories and II reflecting high or low intrapsychic involvement based on general content. In line with our results, both category systems may be reliable tools to examine patients' subjective experience. This is supported by the fact that the agreement between the raters was very high in both encoding systems.

Chemotherapy treatment usually comes with a range of physical, psychological, and psychosocial side effects. Side effects can be clinical syndromes (e.g., depression, anxiety, and cognitive impairment), observable physical problems (e.g., nausea, vomiting, and hair loss), subjective physical problems (e.g., pain and fatigue), as well as psychosocial difficulties (e.g., job and financial problems) [34]. In the present sample, the physical problems represented in somatic complaints were also common; at the same time, these complaints appeared in the three groups with highly different frequencies. The highest occurrence was in the special attention group, as somatic complaints appeared twice more frequently than in the hypnosis groups and 1.5 times more than in the music group. It seems that hypnosis was the most capable to divert attention from disturbing somatic symptoms. It is consistent with a large number of studies having proved that hypnosis can modulate conscious bodily experience like chronic or procedural pain, nausea, and vomiting $[35,36]$.

Internal/external disturbances described the attempt to become involved in the intervention; however, inner thoughts or outside events distracted the patients from becoming involved. Its highest occurrence was in the music group. This could be owing to the fact that special attention did not require a focused immersion on the part of the patients, and it seems that the verbal nature of hypnosis was more successful in orienting attention.

Despite the generally frequent somatic side effects and negative psychological consequences of chemotherapy, pleasant somatic experience was the most dominant response in all three types of interventions. Pleasant somatic experience refers to a state when patients feel relaxed, calm, and free of stress in a mental or physical way. The beneficial effect of achieving relaxed state during chemotherapy has a long history in easing emotional adjustment, anxiety, depression, improving treatmentrelated symptoms, and immune functions, just to mention a few $[37,38]$. It seems that hypnosis providing direct suggestions to achieve a state of relaxation, and music working in a non-verbal fashion are both highly conductive to such a state; however, in the special attention group, pleasant somatic experience showed highest occurrence. This result has an important clinical significance by showing that simple intervention, such as the social support, provided by special attention can generate such beneficial state. It is noteworthy that in the hypnosis and music groups, there are a wider range of other positive involvements (sensory experiences, personal memories, visualisation or elaboration of symbols, described below), whereas in the special attention group, these other positive involvements are almost not present.

Non-verbal sensory experiences, positive personal memories, and elaboration of symbols of suggestion/music occurred in the reports of a relatively small number of patients'. The three interventions did not include direct or non-direct instructions for these three types of involvement - unlike in the case of visualisation of symbols and pleasant somatic experience. Therefore, it is important to highlight that the appearance of these experiences was spontaneous, and their occurrence might denote a greater degree of intrapsychic work. All the three categories 
appeared with highest number in the hypnosis group and they were almost undetectable in the special attention group.

Visualisation of symbols was the highest in the hypnosis groups. In the case of hypnosis, suggestions were overt messages given for therapeutic reasons and contained images to help relieve stress-induced anxiety, as well as metaphors for ego-strengthening, helping to increase motivation for recovery, dealing with the side effects of chemotherapy, activating the inner healing resources, and facilitating immune functions. Music was designed to match the themes, moods, and dynamics of the hypnotic text. It seems that symbols and images similar to the ones given overtly in hypnosis could be evoked by the non-verbal channels of music, but less frequently than in hypnosis. Visualisation of symbols in case of special attention was rare, although detectable. Symbols in this group were always symbols of healing. Elaboration of symbols represents compound images that become personal, original, and unique; they contain meaningful extra details that are obtained from the patient. The occurrence of elaboration of symbols was again highest in the hypnosis group, but it also appeared in music group, where these symbols were activated non-verbally. None of the patients in the special attention group reported symbols in such manner. Both visualisation of symbols and elaboration of symbols have their clinical importance, since previous studies have proven that vividness of imagery is correlated with clinical response to cancer treatment $[23,24]$.

Examining the II, hypnosis led to more intense overt intrapsychic work; however, those who listened to music also claimed to be involved in the therapeutic process, disclosing contents with personal significance or symbolic meaning. Even special attention could trigger intense involvement where healing process appeared in a symbolic way.

In sum, the developed category system seems to be a reliable tool to examine breast cancer patients' subjective experience. Since this study was conducted on a clinical sample, this category system could serve as a useful tool to compare clinical responses and outcomes with the level of patients' involvement. As previous researches indicated $[23,24,27]$, these category systems can serve to measure underlying personal involvement and intrapsychic processes that may modify the effectiveness of a psychological intervention in supportive cancer care. Furthermore, hypnosis as intervention may result in more extended subjective experiences in CI and II.

The limitation of this study is that it was conducted on homogeneous groups of breast cancer patients; therefore, its generalisability remains a question. The content analysis of subjective experiences is a laborious technique; for further research, we suggest a questionnaire to be developed on the basis of the described category systems.

Authors' contribution: AV, ZSK and ÉB summarised the scientific background of the paper. AV, OZ, EJ, and ÉB collected the data and participated in the first step of content analysis. TT and GK performed the content analysis as independent raters. AV carried out the statistical analysis. $\mathrm{AV}, \mathrm{ZSK}, \mathrm{OZ}, \mathrm{EJ}$, and ÉB finalised the text. ÉB is the principal investigator.

Ethical approval: This study is a part of the "Psychological Resources and Healing" research. The Hungarian Medical Research Council Research Ethics Committee approved this research [15530-0/2010-1018EKU (670/PI/10) and 39447-/ 2013/EKU (465/2013)].

Conflict of Interest/Funding: This study is a part of the "Psychological Resources and Healing" research, which is supported by the Hungarian Scientific Research Fund OTKA/NKFI K109187. ÉB is the principal investigator.

\section{REFERENCES}

1. Riskó Á. A daganatos betegségekhez történ alkalamazkodás pszichoszociális folyamata [The psychosocial process of adaptation to cancer]. In: Horti J, Riskó Á, eds. Onkopszichológia a gyakorlatban [Psycho-Oncology in Practice]. Budapest: Medicina; 2006.

2. Mitchell AJ, Chan M, Bhatti H, et al. Prevalence of depression, anxiety, and adjustment disorder in oncological, haematological, and palliative-care settings: a meta-analysis of 94 interview-based studies. Lancet Oncol. 2011;12(2): 160-74.

3. McFarland DC, Holland JC. The management of psychological issues in oncology. Clin Adv Hematol Oncol. 2016; 14(12):999-1009.

4. Matthews H, Grunfeld EA, Turner A. The efficacy of interventions to improve psychosocial outcomes following surgical treatment for breast cancer: a systematic review and metaanalysis. Psychooncology. 2017;26(5):593-607.

5. Casellas-Grau A, Font A, Vives J. Positive psychology interventions in breast cancer. A systematic review. Psychooncology. 2014;23(1):9-19.

6. Bányai É. Hipnózis a pszichoonkológiában [Hypnosis in psycho-oncology]. In: Vértes G, ed. Hipnózis-Hipnoterápia [Hypnosis-Hypnotherapy]. Budapest: Medicina; 2015. p. 241-67.

7. Spiegel D, Cardena E. Disintegrated experience: the dissociative disorders revisited. J Abnorm Psychol. 1991;100(3): 366-78.

8. Varga K. Szuggesztív hatások az orvosi gyakorlatban, különös tekintettel a perioperatív id szakra [Suggestive effects in medical practice, especially in perioperative period]. Psychiatr Hung. 1998;5:529-40.

9. Liossi C, White P, Hatira P. Randomized clinical trial of local anesthetic versus a combination of local anesthetic with selfhypnosis in the management of pediatric procedure-related pain. Health Psychol. 2006;25(3):307-15.

10. Cramer H, Lauche R, Paul A, Langhorst J, Kümmel S, Dobos GJ. Hypnosis in breast cancer care: a systematic review of randomized controlled trials. Integr Cancer Ther. 2015; 14(1):5-15. 
11. Lang EV, Berbaum KS, Faintuch S, et al. Adjunctive selfhypnotic relaxation for outpatient medical procedures: a prospective randomized trial with women undergoing large core breast biopsy. Pain. 2006;126(1-3):155-64.

12. Montgomery GH, Bovbjerg DH, Schnur JB, et al. A randomized clinical trial of a brief hypnosis intervention to control side effects in breast surgery patients. J Natl Cancer Inst. 2007;99(17):1304-12.

13. Montgomery GH, Hallquist MN, Schnur JB, David D, Silverstein JH, Bovbjerg DH. Mediators of a brief hypnosis intervention to control side effects in breast surgery patients: response expectancies and emotional distress. J Consult Clin Psychol. 2010;78(1):80-8.

14. Stanczyk MM. Music therapy in supportive cancer care. Rep Pract Oncol Radiother. 2011;16(5):170-2.

15. Clark M, Isaacks-Downton $\mathrm{G}$, Wells $\mathrm{N}$, et al. Use of preferred music to reduce emotional distress and symptom activity during radiation therapy. J Music Ther. 2006;43(3): 247-65.

16. Cassileth BR, Vickers AJ, Magill L. Music therapy for mood disturbance during hospitalization for autologous stem cell transplantation: a randomized controlled trial. Cancer. 2003;98(12):2723-6.

17. Huang ST, Good M, Zauszniewski JA. The effectiveness of music in relieving pain in cancer patients: a randomized controlled trial. Int J Nurs Stud. 2010;47(11):1354-62.

18. Bradt J, Dileo C, Magill L, Teague A. Music interventions for improving psychological and physical outcomes in cancer patients. Cochrane Database Syst Rev. 2016;8:CD006911.

19. LeCron LM. A method of measuring the depth of hypnosis. Int J Clin Exp Hypn. 1953;1(2):4-7.

20. Shor RE. Three dimensions of hypnotic depth. Int J Clin Exp Hypn. 1962;10(1):23-38.

21. Tart CT. Self-report scales of hypnotic depth. Int J Clin Exp Hypn. 1970;18(2):105-25.

22. Matheson G, Shue KL, Bart C. A validation study of a shortform hypnotic-experience questionnaire and its relationship to hypnotizability. Am J Clin Hypn. 1989;32(1):17-26.

23. Walker LG, Walker MB, Ogston K, et al. Psychological, clinical and pathological effects of relaxation training and guided imagery during primary chemotherapy. Br J Cancer. 1999;80(1-2):262-8.

24. Eremin O, Walker MB, Simpson E, et al. Immuno-modulatory effects of relaxation training and guided imagery in women with locally advanced breast cancer undergoing multimodality therapy: a randomised controlled trial. Breast. 2009;18(1): $17-25$.

25. Kwekkeboom KL, Wanta B. Individual difference variables and the effects of progressive muscle relaxation and analgesic imagery interventions on cancer pain. J Pain Symptom Manage. 2008;36(6):604-15.
26. Kwekkeboom KL, Hau H, Wanta B, Bumpus M. Patients' perceptions of the effectiveness of guided imagery and progressive muscle relaxation interventions used for cancer pain. Complement Ther Clin Pract. 2008;14(3):185-94.

27. Potvin N, Bradt J, Kesslick A. Expanding perspective on music therapy for symptom management in cancer care J Music Ther. 2015;52(1):135-67.

28. Bányai É. "Psychological resources and healing" (The effect of adjuvant hypnotherapy on survival, immune functions and quality of life of intermediate and high-risk breast cancer patients). OTKA K109187 grant, Hungarian Scientific Research Fund, Budapest, 2013.

29. Bányai É, Józsa E, Jakubovits E, Vargay A, Zsigmond O, Horváth Zs. Evidence based research on the role of hypnosis as a psychological intervention in the care of breast cancer patients: a randomised prospective controlled study. Paper presented at 2017 World Congress of Psycho-oncology; 2017 August 14-18; Berlin, Germany.

30. Goldhirsc, A, Wood WC, Coates AS, Gelber RD, Thurlimann B, Senn HJ. Strategies for subtypes - dealing with the diversity of breast cancer: highlights of the St. Gallen International Expert Consensus on the Primary Therapy of Early Breast Cancer. Ann Oncol. 2011;22(8):1736-47.

31. Smith JA, Jarman M, Osborn M. Doing interpretative phenomenological analysis. In: Murray M, Chamberlain K, eds. Qualitative Health Psychology: Theories and Methods. London: Sage; 1999.

32. Downe-Wamboldt B. Content analysis: Method, applications, and issues. Health Care Women Int. 1992;13(3):313-21.

33. Smith JA. Reflecting on the development of interpretative phenomenological analysis and its contribution to qualitative research in psychology. Qual Res Psychol. 2004;1(1):39-54.

34. Wagland R, Richardson A, Armes J, Hankins M, Lennan E, Griffiths P. Treatment-related problems experiences by cancer patients undergoing chemotherapy: a scoping review. Eur J Cancer Care (Engl). 2014;24(5):605-17.

35. Brugnoli M, Pesce G, Pasin E, Basile M, Tamburin S, Polati E. The role of clinical hypnosis and self-hypnosis to relief pain and anxiety in severe chronic diseases in palliative care: a 2-year long-term follow-up of treatment in a nonrandomized clinical trial. Annal Palliat Med. 2017;7(1):17-31.

36. Wortzel J, Spiegel D. Hypnosis in cancer care. Am J Clin Hypn. 2017;60(1):4-17.

37. Luebbert K, Dahme B, Hasenbring M. The effectiveness of relaxation training in reducing treatment-related symptoms and improving emotional adjustment in acute non-surgical cancer treatment: a meta-analytical review. Psychooncology. 2001;10(6):490-502.

38. Gruzelier JH. A review of the impact of hypnosis, relaxation, guided imagery and individual differences on aspects of immunity and health. Stress. 2002;5(2):147-63. 